\title{
Phosphorous Containing poly(amidoamine- organosilicon) (P@PAMAMOS) Flame Retardants: Synthesis and Sol-gel Application on Cotton Fabrics
}

\section{Zhen Zhang}

Nanjing Tech University College of Food Science and Light Industry

Jin lan Li

Nanjing Tech University College of Biotechnology and Pharmaceutical Engineering

Chang nian Zhou

China Textile Information Center

Jie Sun ( $\square$ sunjie5516@126.com )

Nanjing Tech University https://orcid.org/0000-0001-9203-1952

\section{Research Article}

Keywords: Cotton fabrics, P@PAMAMOS, Sol-gel, Flame retardant

Posted Date: November 16th, 2021

DOI: https://doi.org/10.21203/rs.3.rs-978625/v1

License: (c) (i) This work is licensed under a Creative Commons Attribution 4.0 International License.

Read Full License 


\section{Abstract}

A novel hyperbranched phosphorous containing poly(amidoamine-organosilicon) (P@PAMAMOS) was successfully synthesized and the structure was characterized using Fourier transform infrared spectra (FT-IR), ${ }^{1} \mathrm{H}$ NMR and ${ }^{31} \mathrm{P}$ NMR. The cotton fabrics was grafted with P@PAMAMOS by sol-gel methods. The results of P@PAMAMOS modified cotton fabrics were proved by FT-IR and scanning electron microscopy (SEM). The thermal degradation of blank cotton fabrics and P@PAMAMOS modified cotton fabrics were probed by thermogravimetric (TG) analysis, the phenomenon showed that modified cotton fabrics has exquisite thermal stability, when the temperature reached $700^{\circ} \mathrm{C} \otimes$ the char residues of $A_{10}$ treated cotton, $\mathrm{B}_{10}$ treated cotton, $\mathrm{C}_{10}$ treated cotton were $29.5 \%, 34.5 \%, 28.8 \%$, respectively. The combustion properties of cotton fabrics were tested by limiting oxygen index (LOI) and vertical burning test. The untreated cotton fabrics was completely burned and the LOI value reached $18.0 \%$, however the char diameter of 20wt\% P@PAMAMOS modified cotton fabrics was reduced $3.2 \mathrm{~cm}$ and LOI value increase to $31.2 \%$, this means that P@PAMAMOS modification shows desirable flame retardancy.

\section{Introduction}

Due to its comfortable, green, and cheap advantages, cotton is the one of most popular natural fibers, and is widely used in apparel, domestics, and industries textile. Despite of its numerous advantages, inflammability, easy to breed bacteria and electrolyte-needing dyeing are still ticklish problems for cotton fabric. When it is used in some special place, such as automobile textiles, indoor decoration, or textile product for public area, such as hospital and military, the requirement for its flame retardant and antibacterial is much high.

Halogen containing and phosphorous based compounds are the commonly used two series of flame retardants (FRs). Owing to the releasing of toxic gas during combustion, the halogen containing flame retardants have been denounced for a long time; the products relating to halogen-based flame retardants are decreasing.

Since the prohibition of traditional halogen-based fire retardant, seeking for efficient, safe, and permanent halogen-free fire retardant has been research hotspots. Among all the halogen-free fire retardants, phosphorous compounds, inorganic compounds, and even their hybrids compounds are mentioned and investigated frequently and constantly.

Phosphorus-based flame retardants (FRs) have been exploited commercially for a long time. Ammonium phosphate was the first used of phosphorus FRs, which trace back to the eighteenth century ago. Nowadays, the demands for phosphorus FRs are strongly raising, and a lot of new products and new formulations have been and being developed. N-hydroxymethyl-3-(dimethoxyphosphonyl) propionamide which are typified by the former Ciba (and now Huntsman) product Pyrovatex $\mathrm{CP}^{\mathrm{R}}$ is one of the famous phosphorous containing fire retardants; it can react with the cellulose fiber and endow the fabrics durable flame-retardant ability; However, it has the problem of formaldehyde release (Horrocks 2011). Referring to 
the extinguish mechanism of phosphorous containing fire retardant, it is often believed in the intumescent theory (Zhang et al. 2014; Chen et al. 2011; Wang and Cai 2017; Lessan et al. 2011; Yan et al. 2012).

Cyclotriphosphazene derivatives are the mainly researched FRs (Mayer-Gall et al. 2015; Dutkiewicz et al. 2018; Edwards et al. 2015). And some natural phosphorous containing compounds, such as phytate, can be used in the preparation of FRs (Feng et al. 2017; Wang 2020; Jiang et al. 2018; Cheng et al. 2020; Zhang et al. 2012). Nitrogen element is considered having a positive effect in FR. The facilitation of nitrogen in phosphorus FRs was observed and confirmed for a long time. While being used with phosphorus $\mathrm{FR}$, the synergistic effect of $\mathrm{N}$ and $\mathrm{P}$ can remarkably decrease amounts of almost all gas products and the disappearance of some gas products, the toxic gas, acrolein, is entirely absent in the combustion of cotton treated with N and P containing FRs (Nakanishi et al. 2000; Gaan and Sun 2007). Inorganic compounds are non-combustible materials and thus physically dilute the amount of combustible polymer in the solid phase and can increase the char residues noticeably. Alumina, antimony, boron, silicon compounds, and even clays are the mostly wildly researched inorganic FRs. However, these inorganic FRs are used in form of doping, which is subjected to leaking, bad endurance and tactility.

Because of its cheap, safe, and easily available properties, silicon is the most active researched inorganic element in FRs application. More important, silicon can link with carbon covalently to form organosilicon; these Si-C bonds are firmly, water and solvent tolerant, that enables the chemically linked organicinorganic hybrid materials to prepare easily, and to apply widely and safely.

Generally, the role of silica in FRs is to form of a silicon-based protective surface layer on the surface of the substrates. This silicon-based can have an effect similar with oxygen barrier and thermal shield. Furtherly, another important superiority of organosilicon compounds is that, it makes an interesting group capable of forming durable chemical bonds with various inorganic and organic substrates, including cotton textile surfaces. These chemical bonds can surmount the shortcoming of bad endurance, which is a ubiquitous problem in inorganic compounds finishing (Horrocks 2011; Amiri and Rahimi 2016; Chen and Jiao 2009; Visakh and Yoshihiko 2015).

Hyperbranched polymers (HBPs) are highly branched macromolecules with three-dimensional dendritic architecture. Since they emerged and were discovered, HBPs have attracted increasing attention owing to their unique and properties, versatile application, and greater availability as compared with dendrimers (Jikei and Kakimoto 2001; Gao and Yan 2004; Mahapatra and Karak 2007; Huang and Shi 2007). The applications of dendrimers or HBPs have been developed in various fields, such as micelles and encapsulation, liquid crystals, layers, electroactive and electroluminescent devices, sensors, conductive and ionic conductive polymers, photochemical molecular devices (energy and electron transfer), nonlinear optics, catalysts, Biochemicals and pharmchemicals, and so on (Inoue 2000). There are also some researches on the application of HBPs in FR. 
Battig et al. (2019) have synthesized a series of hyperbranched phosphorus flame retardants and tested their use in epoxy resins. They found that these hb-polymeric FRs have improved miscibility and thermal stability, leading to high FR performance even at low loadings. Polymeric, complex FRs increase flame retardancy, alleviate negative effects of low molecular weight variants. Using the renewable material itaconic anhydride, a novel hyperbranched FR polymer (referred to as ITA-HBP) was synthesized; and it had a flame retarding ability in epoxy resins at a very low phosphorus content (Zhang 2020). Ruchenstein and $\mathrm{Yin}$ (2000) has synthesized $\mathrm{SiO}_{2}$-PAMAM inorganic/organic hybrids by a Michael addition reaction with 3-(trimethoxysilyl) propyl acrylate (TPA) and PAMAM dendrimers in THF solution.

Polyamidoamine (PAMAM) is one of the most famous HBPs, which can be obtained straightforwardly with common chemical reagents; there are many references about the structures, physicochemical properties, and application about PAMAM (Sadeghi-Kiakhani and Tehrani-Bagha 2016; Arteta et al. 2013; Mecke et al. 2004; Tsubokawa and Takayama 2000; Sayed-Sweet et al. 1997). The studies about PAMAM in salt-free dyeing, antimicrobial, color fixation and stabilizer have been investigated detailly (Wang et al. 2014; Zolriasatein et al. 2013; Zhang et al. 2008; Zhang et al. 2009; Marty et al. 2008). However, the application of PAMAM in FR of textile products is still rare. Subjected to the defect of lacking in covalent bonds between PAMAM and cellulose fibers, the cotton fabrics must be treated by oxidation or with crosslinking agent in prior to guarantee covalent bonds between PAMAM and cellulose fibers. The cost of these methods is the strength reduction or operation lengthening (Wang et al. 2014; Zhang et al. 2008). Fortunately, this conundrum can be settled by combination of HBPs and sol-gel technology.

The sol-gel technology in textile finishing processes has taken much attention for decades. Because of the merits of less chemical usage, low-temperature process, simple application equipment, sol-gel technology is well received in textile plants. Besides of the application in antimicrobial, UV protection, color fixation, durable press, hydrophobicity (or superhydrophobicity), insecticide, fragrance and selfcleaning finishing of textile industry, sol-gel process has been used in FR finishing as well (Grancaric et al. 2017; Foksowicz-Flaczyk et al. 2016). El-Shafei et al. (2015) have conducted a flame retardant and antibacterial finishing for cotton fabrics with $\mathrm{TiO}_{2}$ nanoparticles and chitosan phosphate by a sol-gel method. Through a layer-by-layer assembly and sol-gel process, Jiang et al. completed a durable flameretardant and antidroplet finishing of polyester fabrics with flexible polysiloxane and phytic acid (Dutkiewicz et al. 2018; Jiang et al. 2018; Costa et al. 2012; Hou et al. 2009; Liu et al. 2011; Brancatelli et al. 2011). Wang et al. (2015) deposited an intumescent coating composed of a nitrogen-modified silane hybrid and phytic acid on layer-by-layer assembly and sol-gel process.

Moreover, sol-gel technology makes realizing multifunctional properties in one step which is not easy by conventional textile finishing because of incompatibility of chemical materials; This all-in-one process reduce the procedure and improve production efficiency (Foksowicz-Flaczyk et al. 2016; Camlibel and Arik 2017; Lin et al. 2019). FR and antibacterial finishing for cellulosic fabrics was be realized by solgel method (El-Shafei et al. 2015; Alongi et al. 2012). 
The aim of this work was to integrate the characteristics of N-P-Si FRs, PAMAM and sol-gel technology in one compound, to synthesis phosphorous containing poly(amidoamine-organosilicon) (P@PAMAMOS), and to investigate its application and properties on fabrics modification. This P@PAMAMOS FRs was prospected to have N-P synergic effect and inorganic/organic superposition effect in FR; PAMAM has a feature of three-dimensional dendritic architecture and excellent water solubility.

\section{Experimental}

\subsection{Materials}

The pretreated, mercerized, and undyed woven pure cotton poplin fabrics were provided by Mercury Home Textile Co., Ltd (Shanghai, China). Fabric specifications were as follows: weight $150 \mathrm{~g} / \mathrm{m}^{2}$; warp 15 threads $/ \mathrm{cm}$; weft 8 threads $/ \mathrm{cm}$. Dimethyl phosphite, dimethyl maleate (DMM), and methyl acrylate were purchased from Meryer Chemical Technology Co., Ltd (Shanghai, China); Sodium methoxide and Diethylenetriamine (DETA) were from Shanghai Lingfeng Chemical Reagent Co., Ltd (Shanghai, China); 3Glycidoxypropyltrimethoxysilane (KH 560) was provided free by Yangzhou Lida Resin Co., Ltd (Yangzhou, China). Expect KH 560 was technical-grade, other chemicals were of analytical grade. All chemicals were used as received, without further purification.

\subsection{Synthesis of Pentamethyl 2-phosphonobutane-1,2,4-tricarboxylate (PM-PBTC)}

The synthesis route and reaction mechanism of pentamethyl 2-phosphonobutane-1,2,4-tricarboxylate (PM-PBTC) was given in Scheme 1. The synthesis operation was similar with the method of Wang et al. (2007). and was depicted simply here.

A mixture of dimethyl phosphite $(22 \mathrm{~g}, 0.2 \mathrm{~mol})$ and DMM $(28.8 \mathrm{~g}, 0.2 \mathrm{~mol})$ was stirred in a condenser installed four-necked flask at room temperature, then the catalyst, sodium methoxide $(0.1 \mathrm{~g}, 1.85 \mathrm{mmol})$ was added while stirring. After heating the reaction mixture to $60^{\circ} \mathrm{C}$ and keeping stirring at $60{ }^{\circ} \mathrm{C}$ for $2 \mathrm{~h}$, the reaction temperature was taken down to $30^{\circ} \mathrm{C}$; methyl acrylate $(17.22 \mathrm{~g}, 0.2 \mathrm{~mol})$ and another portion of sodium methoxide $(0.1 \mathrm{~g}, 1.85 \mathrm{mmol})$ were added. The reaction was kept for $3 \mathrm{~h}$, then the products, PMPBTC, was obtained. The products didn't need separation and purification, and were saved for next step synthesis.

\subsection{Preparation of P@PAMAMOS sol}

Phosphorous containing poly(amidoamine-organosilicon) (P@PAMAMOS) solution was prepared by a one-pot method. The operation is sketched as follows. The mixture of DETA $(31.0 \mathrm{~g}, 0.3 \mathrm{~mol})$ and absolute methanol $(20 \mathrm{~mL})$ was dropwise added into the mixture of PM-PBTC $(68 \mathrm{~g}, 0.2 \mathrm{~mol})$ and DMM $(14.4 \mathrm{~g}, 0.1 \mathrm{~mol})$, in $30 \mathrm{~min}$ while the reaction system was stirring. After the addition,

the mixture was stirred for $1 \mathrm{~h}$ at reflux condition, then the reflux condenser was dismantled but a reduced pressure distillation apparatus was fixed subsequently. The reaction was kept for about $4 \mathrm{~h}$ at $90{ }^{\circ} \mathrm{C}$ to 
remove methanol continuously. With methanol was removed, the viscosity of the mixture increased gradually. The reaction temperature was $120^{\circ} \mathrm{C}$ for another $1 \mathrm{~h}$, then the reaction temperature dropped down to $40{ }^{\circ} \mathrm{C}$, the route of synthesis of P@PAMAM was given Scheme 2 .

Then $\mathrm{KH} 560(23.6 \mathrm{~g}, 0.1 \mathrm{~mol})$ was added. The mixture was stirred for $30 \mathrm{~min}$ at $40^{\circ} \mathrm{C}$, the clear and viscous product was obtained. Deionized water $(101.8 \mathrm{~mL})$ was dropped and churned for 2 h sequentially. Finally, a light yellow and homogenous of P@PAMAMOS sol was prepared (with concentration 50\%), the synthesis route of P@PAMAMOS sol was shown Scheme 3.

The P@PAMAMOS FRs with phosphorous, Nitrogen and silicon content was prepared in the same above, the difference is that dosages of PM-PBTC, diethylene triamine and KH560, all the P@PAMAMOS FRs were prepared in $50 \%$ concentration.

We have synthesized three types (A, B, C) of P@PAMAMOS sol, and the formulations of each type were showed in Table 1. And their element content of P, N, Si in P@PAMAMOS were given in table 1.

The structure of unhydrolyzed P@PAMAMOS was confirmed by ${ }^{1} \mathrm{H}$ NMR and ${ }^{31} \mathrm{P}$ NMR testing, before added the deionized water, the results was shown in Fig.1 and Fig. $2 .{ }^{1} \mathrm{H}$ NMR (400 MHz, DMSO-d6): 80.77-0.87, $\mathrm{Si}_{-} \mathrm{CH}_{2} \mathrm{CH}_{2}$ (b); 81.17-1.29, Si- $\mathrm{CH}_{2} \mathrm{CH}_{2}$ (c); 62.09-2.30, $\mathrm{CH}_{2} \mathrm{CONH}$ (o), primary amine $\mathrm{NH}_{2}(\mathrm{n}) ; \delta 2.47-2.73, \mathrm{NH}-\mathrm{CH}_{2}(\mathrm{~h})$, secondary amine $\mathrm{NH}(\mathrm{i}), \mathrm{CH}_{2}-\mathrm{NH}(\mathrm{j}) ; 83.25-3.39$, $\mathrm{O}-\mathrm{CH}_{2}(\mathrm{~d}), \mathrm{CH}_{2} \mathrm{O}(\mathrm{e}) ; \delta 3.43-3.62, \mathrm{Si}-\mathrm{OCH}_{3}(\mathrm{a}), \mathrm{CH}-\mathrm{OH}(\mathrm{g}), \mathrm{CONH}_{-} \mathrm{CH}_{2}(\mathrm{k}), \mathrm{COCH}(\mathrm{m}), \mathrm{P}-$ $\mathrm{OCH}_{3}(\mathrm{p}) ; 65.8$ is attributed to $\mathrm{CH}-\mathrm{OH}$ (f); 67.26 belongs to $\mathrm{CONH}$ (l).

The P@PAMAMOS gel was synthesis from the P@PAMAMOS sol in oven at $110{ }^{\circ} \mathrm{C}$ for $20 \mathrm{~h}$, and P@PAMAMOS gel $(0.07 \mathrm{~g})$ was ground into powder and mixed with $\operatorname{KBr}(0.3 \mathrm{~g})$ sufficiently then the mixture was pressed into flakes. The FT-IR of the gel was recorded with a spectrometer (Nicolet iS10, Thermo Fisher Scientific Inc., USA) in the range of $4000-500 \mathrm{~cm}^{-1}$. The results were shown in Fig.3.

Fig.3, the peaks at $3418 \mathrm{~cm}^{-1}$ belongs to the stretching vibration of amine groups in P@PAMAMOS (Wang et al. 2014; Zhang et al. 2007; Zhang et al. 2021), 2850-2950 $\mathrm{cm}^{-1}$ were attributed to the stretching vibration of methyl and methylene(C-H) in P@PAMAMOS (Wang et al. 2014), the strong absorptions at $1653 \mathrm{~cm}^{-1}$ were characteristic of the carbonyl stretching vibration of in amide bonds(-CONH-), and bending vibration of amine groups (N-H) appears at $1561 \mathrm{~cm}^{-1}$ (Wang et al. 2014; Zhang et al. 2007; Zhang et al. 2021). The peak at $1466 \mathrm{~cm}^{-1}$ indicated the existence of the methylene group bending vibration (Zhang et al. 2021); the absorptions at $1200 \mathrm{~cm}^{-1}$ was caused from stretching vibration of $P=0$ (Zhang et al. 2020; Liu et al. 2020; Jia et al. 2017). The appearance of characteristic peak at $1114 \mathrm{~cm}^{-1}$ was assigned to P-O-C bonds (Liu et al. 2020; Wang and Cai 1989; Zheng et al. 2016); The characteristic absorptions peaks at 1040 and $694 \mathrm{~cm}^{-1}$ coincide with Si-O-Si bending vibration (Brancatelli et al. 2011; Zhang et al. 2021; Zhang et al. 2020; Liu et al. 2020).

\subsection{Cotton fabrics grafted with P@PAMAMOS by sol-gel method}


The cotton fabrics were treated with the P@PAMAMOS sol, the operation method as follows: first, cotton fibers were immersed in the prepared P@PAMAMOS sol, then the treated fabrics were squeezed by uniform squeezer, repeat the same operation again, subsequently the wet cotton fabrics were dried naturally, finally, cotton fabrics were cured at $120^{\circ} \mathrm{C}$ for $5 \mathrm{~min}$ in the oven. The interaction mechanism between P@PAMAMOS and cotton fabrics was Scheme 4.

The blank sample were treated with the similar process, the difference is that cotton fibers were immersed in deionized water, not containing P@PAMAMOS. These samples are denoted as $M-x$ where $M$ stands for the type of P@PAMAMOS, $x$, the weight percentage P@PAMAMOS sol content in the work bath; e.g., sample $A_{3}$ represents the cotton fabrics treated with P@PAMAMOS sol of type A in $3 \%$ concentration.

\subsection{FT-IR spectra}

The FT-IR spectra of the cotton fabric samples were tested with a Nicolet 5700 FT-IR spectrometer (Thermo Fisher Scientific Inc., Waltham, MA, USA) over the wavenumber range of $4000-500 \mathrm{~cm}^{-1}$ using $\mathrm{KBr}$ pellets.

\subsection{Thermogravimetric analysis (TGA)}

Thermogravimetric analysis (TGA) of all samples was fulfilled by a TA Instruments Q50 TGA thermobalance at a linear heating rate of $10{ }^{\circ} \mathrm{C} / \mathrm{min}$ from 30 to $700{ }^{\circ} \mathrm{C}$ under nitrogen flow $(60 \mathrm{ml} / \mathrm{min})$. The experimental error was $0.5 \%$ on weight and $1{ }^{\circ} \mathrm{C}$ on temperature.

\subsection{Scanning electron microscopy (SEM)}

SEM (JSM-5900, Japan) was applied to analysis the surface form of cotton fabrics. The samples were sputter-coated with a layer of gold in vacuum and $2 \mu \mathrm{m}$ thick cotton fiber in sputter coater before observation.

\subsection{Vertical burning test}

The vertical burning test was conducted by a method similar to GB/T 5455- 2014 (Textiles-Burning behaviour-Determination of damaged length, afterglow time and after flame time of vertically oriented specimens), which is equivalent to ASTM Standard Method D6413.

The burning behavior of the fabrics for the vertical burning test was classified according to GB/T 175912006.

\subsection{Limiting oxygen index test}

Limiting oxygen index (LOI) was tested by GB/T 5454-1997, using M606B digital oxygen index apparatus.

\section{Results And Discussion}




\subsection{FT-IR study of modified and blank cotton fabrics}

The FT-IR spectra of the P@PAMAMOS modified cotton fabrics and blank sample are presented in Fig.4. The wide peaks at $3500-3000 \mathrm{~cm}^{-1}$ are caused by the stretching vibrations of hydrogen bonded $\mathrm{O}-\mathrm{H}$. In compared with untreated cotton fiber, cotton fabrics grafted with P@PAMAMOS have a stronger peak at $3500-3000 \mathrm{~cm}^{-1}$, which is contradicts the previous conclusion (Brancatelli et al. 2011). This phenomenon can be explained that the overlapping peaks of the stretching vibration of amino group and the cellulose hydrogen bonded (Zhang et al. 2021), indicating cotton fabrics have been graft by P@PAMAMOS. The adsorption peak at $1649 \mathrm{~cm}^{-1}$ is due to the stretching vibration of $-\mathrm{CONH}$-, the characteristic peaks at $1566 \mathrm{~cm}^{-1}$ and $1430 \mathrm{~cm}^{-1}$ ascribed of the primary amine(-NH-) appears (Wang et al. 2014; Zhang et al. 2007; Zhang et al. 2021). The stretching vibration of $P=0$ was shown in $1114 \mathrm{~cm}^{-1}$ (Zhang et al. 2020; Liu et al. 2020; Jia et al. 2017), in compared with other modified cotton fabrics, the adsorption peak of the $B_{10}$ treated cotton was stronger, which is explained that the $B_{10}$ treated cotton has the highest phosphonium content. The weak peak at $774 \mathrm{~cm}^{-1}$ are the characteristics of Si-O-Si stretching bands (Brancatelli et al. 2011), indicating the existence of $\mathrm{SiO}_{2}$ matrix. At $774 \mathrm{~cm}^{-1}$, the peak intensity of $\mathrm{C}_{10}$ treated cotton was weaker, the phenomenon was interpreted that when cotton fabric treated with sols of silica, and the thin membrane was formed on the surface of cotton fabric, because of the shelter effect of the thin film, the characteristic peak intensity of cellulose would decrease.

\subsection{Thermal behaviors of modified and blank cotton fabrics}

Thermo gravimetric analysis (TGA) and DTG are important means to revealing the thermal behaviors of materials (Yuen 2007). TGA and DTG results of P@PAMAMOS-treated and blank cotton fibers are displayed in Fig. 5 and table 2 under nitrogen atmosphere. The weight of the blank sample was slowly degraded between 0 and $200^{\circ} \mathrm{C}$, which is caused by water volatilization. For the blank sample, the first degradation temperature of blank sample occurs from $280^{\circ} \mathrm{C}$ to $390^{\circ} \mathrm{C}$. The main degradation of untreated cotton arrives at $370^{\circ} \mathrm{C}$ with approximately $55 \%$ weight loss. This result can be explained that cellulose thermally decomposed and generated volatile gases at this stage (Liu et al. 2020; Alongi and Malucelli 2015). The weight loss was small after $390^{\circ} \mathrm{C}$, the char residue was about $12.7 \%$ at $700^{\circ} \mathrm{C}$. There are three degradation stages for the modified cotton fabrics, the initial pyrolysis stage was below $120^{\circ} \mathrm{C}$, the modified cotton fabrics weight was slowly degraded, which is similar with untreated cotton, with approximately $2 \%$ weight loss for three sample at $120^{\circ} \mathrm{C}$. The pyrolysis temperature of second stage was between 120 and $260^{\circ} \mathrm{C}$, the temperature of maximumrate pyrolysis rate were at $174^{\circ} \mathrm{C}, 160^{\circ} \mathrm{C}$, $170^{\circ} \mathrm{C}$ with weight losses of $3.1 \%, 5.3 \%, 6.0 \%$ for $A_{10}$ treated cotton, $B_{10}$ treated cotton, $C_{10}$ treated cotton, respectively. Temperature range at this stage is wide, the reasons was speculated that the weight loss was mainly caused by evaporation of water below $200^{\circ} \mathrm{C}$, the phosphorus element in the P@PAMAMOS forms phosphoric acid, phosphoric acid can catalyze cellulose to promote dehydration (Liu et al. 2020), cause the weight loss of cellulose at $200-260^{\circ} \mathrm{C}$. The third pyrolysis stage was at $260-345^{\circ} \mathrm{C}$, the maximum weight losses of $\mathrm{A}_{10}$ treated cotton, $\mathrm{B}_{10}$ treated cotton, $\mathrm{C}_{10}$ treated cotton, occurred at about $330^{\circ} \mathrm{C}, 315^{\circ} \mathrm{C}, 327^{\circ} \mathrm{C}$ with weight losses of $44.5 \%, 39.9 \%, 42.4 \%$, respectively. Compared to untreated 
cotton, the temperature of the maximum weight losses of treated cotton advanced $44-55^{\circ} \mathrm{C}$, which is due to catalysis of phosphonic acid (Liu et al. 2020); $\mathrm{B}_{10}$ treated cotton advanced $12-15^{\circ} \mathrm{C}$ than other samples, which is also explained by catalysis of phosphonic acid. The char residues of $A_{10}$ treated cotton, $B_{10}$ treated cotton, $C_{10}$ treated cotton were $29.5 \%, 34.5 \%, 28.8 \%$ at $700^{\circ} \mathrm{C}$, respectively. In contrast to untreated cotton, modified cotton fabrics have better thermal stability and $\mathrm{B}_{10}$ treated cotton which contains the most phosphorus element show excellent thermo stability. The reason can be speculated that the phosphorus element in P@PAMAMOS forms phosphoric acid, which can catalyze cellulose to promote dehydration and carbonization, contribute cellulose to formed char residue, silicon element can form $\mathrm{SiO}_{2}$ to wrapped on the surface of the cotton fiber and further cross-linking react, suppressing further decomposition of cellulose (Zhang et al. 2020).

\subsection{SEM morphologies of modified and blank cotton fabrics}

Fig.6a, b shows the surface shape of blank cotton fabrics, Fig.6c is the surface morphologies of their cross-section. It shows that the surface of blank samples is smooth, flat, and clean, the edge of crosssection of untreated cotton fibers is neat. Fig.6d, e is the surface shape of P@PAMAMOS modified cotton fabrics, and Fig. $6 \mathrm{f}$ is the surface morphologies of modified cotton fabrics cross-section.

From the pictures, the surface of untreated cotton fiber is relatively smooth, indicating that there is no other ingredient on it. However, cotton fabrics grafted with P@PAMAMOS have a relatively rough and bumpy surface, which is caused from P@PAMAMOS deposited on cotton fiber surface. From Fig.6f the center of the grafted fiber cross-section is similar with blank samples, which is due to graft of P@PAMAMOS appeared only on cotton fiber surface, but not inside the fiber.

\subsection{Flame retardancy of modified and blank cotton fabrics}

The results of vertical flammability test and limiting oxygen index (LOI) of modified and blank cotton fabrics are shown in Fig.7 and table 3, respectively. The blank sample was completely burned, with 12.3s of afterflame time, $13.4 \mathrm{~s}$ of afterglow time and LOI value of $18.0 \%$, this means that blank sample cannot form a char layer to effectively reduce the heat released during combustion. However, P@PAMAMOS modified cotton fabrics shows desirable flame retardancy, the char length of cotton fabrics grafted with 5wt\% P@PAMAMOS decrease to $7.3 \mathrm{~cm}$ and showed a higher LOI value, reached $24.6 \%$, indicating that the synergistic effects of nitrogen, phosphorus and silicon form condensed and intumescent char layers to reduce the heat discharged during ignition (Qian 2014). With the increase of amount of P@PAMAMOS, LOI value of cotton fabrics gradually increased and char length gradually decreased. When the P@PAMAMOS reached $20 \%$, the char diameter of treated cotton fabrics was reduced to $3.2 \mathrm{~cm}$ and LOI value increase to $31.2 \%$. The results demonstrate that P@PAMAMOS can improve cotton fabrics flame retardancy.

\section{Conclusions}


The P@PAMAMOS was synthesized and affirmed by FT-IR, ${ }^{1} \mathrm{H}$ NMR and ${ }^{31} \mathrm{P}$ NMR, the cotton fabrics were grafted with P@PAMAMOS by sol-gel method. The alteration effects were evaluated by FT-IR and SEM, vertical flammability, and thermal behaviors were investigated. The SEM showed P@PAMAMOS gel accumulate on the surface of cotton fibers. The TG analysis demonstrated that the char residues of $A_{10}$ treated cotton, $B_{10}$ treated cotton, $C_{10}$ treated cotton were $29.5 \%, 34.5 \%, 28.8 \%$ at $700^{\circ} \mathrm{C}$, respectively, which is better than blank cotton fabrics. The vertical flammability test indicated that modified cotton showed great flame retardancy, and the P@PAMAMOS reached 20\%wt, the char diameter of treated cotton fabrics was reduced to $3.2 \mathrm{~cm}$ and LOI value increase to $31.2 \%$. The P@PAMAMOS modified cotton fabric displayed high flame retardancy.

\section{Declarations}

\section{Acknowledgement}

This work was supported by the National Natural Science Foundation of China (Grant No. 21406108).

We have no potential conflict of interest.

\section{References}

Alongi J, Colleoni C, Malucelli G, Rosace G (2012) Hybrid phosphorus-doped silica architectures derived from a multistep sol-gel process for improving thermal stability and flame retardancy of cotton fabrics. Polym Degrad Stab 97:1334-1344.

Alongi J, Malucelli G (2015) Cotton flame retardancy: state of the art and future perspectives. RSC Adv 5:24239-24263.

Amiri S, Rahimi A (2016) Hybrid nanocomposite coating by sol-gel method: a review. Iran Polym J 25:559577.

Arteta MY, Eltes F, Campbell RA, Nylander T (2013) Interactions of PAMAM dendrimers with SDS at the solid-liquid interface. Langmuir 29:5817-5831.

Battig A, Markwart JC, Wurm FR, Schartel B (2019) Hyperbranched phosphorus flame retardants: multifunctional additives for epoxy resins. Polym Chem 10:4346-4358.

Brancatelli G, Colleoni C, Massafra MR, Rosace G (2011) Effect of hybrid phosphorus-doped silica thin films produced by sol-gel method on the thermal behavior of cotton fabrics. Polym Degrad Stab 96:483490.

Camlibel NO, Arik B (2017) Sol-Gel applications in textile finishing processes. Recent applications in SolGel synthesis Chapter 13:253-273. 
Chen J, Liu S, Zhao J (2011) Synthesis, application, and flame retardancy mechanism of a novel flame retardant containing silicon and caged bicyclic phosphate for polyamide 6. Polym Degrad Stab 96:15081515.

Chen XL, Jiao C (2009) Synergistic effects of hydroxy silicone oil on intumescent flame retardant polypropylene system. J Polym Res 44:1010-1014.

Cheng XW, Tang RC, Guan JP, Zhou SQ (2020) An eco-friendly and effective flame retardant coating for cotton fabric basedon phytic acid doped silica sol approach. Prog Org Coat 141:105539.

Costa DO, Dixon SJ, Rizkalla AS (2012) One and three-dimensional growth of hydroxyapatite nanowires during sol-gel-hydrothermal synthesis. ACS Appl Mater Interfaces 4:1490-1499.

Dutkiewicz M, Przybylak M, Januszewski R, Maciejewski H (2018) Synthesis and flame retardant efficacy of hexakis(3-(triethoxysilyl) propyloxy)cyclotriphosphazene/silica coatings for cotton fabrics. Polym Degrad Stab 148:10-18.

Edwards B, Hauser P, El-Shafei (2015) A nonflammable cellulosic substrates by application of novel radiation-curable flame retardant monomers derived from cyclotriphosphazene. Cellulose 22:275-287.

El-Shafei A, ElShemy M, Abou-Okeil A (2015) Eco-friendly finishing agent for cotton fabrics to improve flame retardant and antibacterial properties. Carbohydr Polym 118:83-90.

Feng YJ, Zhou Y, Li DK, He S, Zhang FX, Zhang GX (2017) A plant-based reactive ammonium phytate for use as a flame-retardant for cotton fabric. Carbohydr Polym 175:636-644.

Foksowicz-Flaczyk J, Walentowska J, Przybylak M, Maciejewski H (2016) Multifunctional durable properties of textile materials modified by biocidal agents in the sol-gel process. Surf Coat Technol 304:160-166.

Gaan S, Sun G (2007) Effect of phosphorus and nitrogen on flame retardant cellulose: A study of phosphorus compounds. J Anal Appl Pyrolysis 78:371-377.

Gao C, Yan D (2004) Hyperbranched polymers: from synthesis to applications. Prog Polym Sci 29:183275.

Grancaric AM, Colleoni C, Guido E, Botteri L, Rosace G (2017) Thermal behaviour and flame retardancy of monoethanolamine-doped sol-gel coatings of cotton fabric. Prog Org Coat 103:174-181.

Horrocks AR (2011) Flame retardant challenges for textiles and fibres: new chemistry versus innovatory solutions. Polym Degrad Stab 96:377-392.

Hou AQ, Shi YQ, Yu YH (2009) Preparation of the cellulose/silica hybrid containing cationic group by solgel crosslinking process and its dyeing properties. Carbohydr Polym 77:201-205. 
Huang ZG, Shi WF (2007) Synthesis and properties of a novel hyperbranched polyphosphate acrylate applied to UV curable flame retardant coatings. Eur Polym J 43:1302-1312.

Inoue K (2000) Functional dendrimers, hyperbranched and star polymers. Prog Polym Sci 25:453-571.

Jia YL, Hu YW, Zheng DD, Zhang GX, Zhang FX, Liang YJ (2017) Synthesis and evaluation of an efficient, durable, and environmentally friendly flame retardant for cotton. Cellulose 24:1159-1170.

Jiang Z, Wang C, Fang S, Ji P, Wang H, Ji C (2018) Durable flame-retardant and antidroplet finishing of polyester fabrics with flexible polysiloxane and phytic acid through layer-by-layer assembly and sol-gel process. J Appl Polym Sci 135:46414.

Jikei M, Kakimoto MA (2001) Hyperbranched polymers: a promising new class of materials. Prog Polym Sci 26:1233-1285.

Lessan F, Montazer M, Moghadam MB (2011) A novel durable flame-retardant cotton fabric using sodium hypophosphite, nanoTiO 2 and maleic acid. Thermochim Acta 520:48-54.

Lin D, Zeng X, Li H, Lai X, Wu T (2019) One-pot fabrication of superhydrophobic and flame-retardant coatings on cotton fabrics via sol-gel reaction. J Colloid Interface Sci 5331:198-206.

Liu J, Dong CH, Zhang Z, Kong DZ, Sun H, Lu Z (2020) Multifunctional flame-retarded and hydrophobic cotton fabrics modified with a cyclic phosphorus/polysiloxane copolymer. Cellulose 27:3531-3549.

Liu JY, Huang WQ, Xing YJ, Li R, Dai JJ (2011) Preparation of durable superhydrophobic surface by solgel method with water glass and citric acid. J Sol-Gel Sci Technol 58:18-23.

Mahapatra SS, Karak N, (2007) s-Triazine containing flame retardant hyperbranched polyamines: Synthesis, characterization, and properties evaluation. Polym Degrad Stab 92:947-955.

Marty JD, Martinez-Aripe E, Mingotaud AF, Mingotaud C (2008) Hyperbranched polyamidoamine as stabilizer for catalytically active nanoparticles in water. J Colloid Interface Sci 326:51-54.

Mayer-Gall T, Knittel D, Gutmann JS, Opwis K (2015) Permanent flame retardant finishing of textiles by allylfunctionalized polyphosphazenes. ACS Appl Mater Interfaces 7:9349-9363.

Mecke A, Lee I, Jr JRB, Holl MMB, Orr BG (2004) Deformability of poly(amidoamine) dendrimers. Orr Eur Phys J E 14:7-16.

Nakanishi S, Masuko F, Hori K, Hashimoto T (2000) Pyrolytic gas generation of cotton cellulose with and without flame retardants at different stages of thermal degradation: effects of nitrogen, phosphorus, and halogens. Text Res J 70:574-583. 
Qian X et al (2014) Organic/inorganic flame retardants containing phosphorus, nitrogen, and silicon: Preparation and their performance on the flame retardancy of epoxy resins as a novel intumescent flame retardant system. Mater Chem Phys 143:1243-1252.

Ruchenstein E, Yin WS (2000) $\mathrm{SiO}_{2}$-Poly(amidoamine) Dendrimer inorganic/organic hybrids. J Polym Sci PartA: Polym Chem 38:1443-1449.

Sadeghi-Kiakhani M, Tehrani-Bagha AR (2016) Retarding action of poly(amidoamine) dendrimers and cationic gemini surfactants in acrylic dyeing. Dyes Pigm 25:323-330.

Sayed-Sweet Y, Hedstrand DM, Spinder R, Tomalia DA (1997) Hydrophobically modified poly(amidoamine) (pamam) dendrimers: their properties at the air-water interface and use as nanoscopic container molecules. J Mater Chem 7:1199-1205.

Tsubokawa N, Takayama T (2000) Surface modification of chitosan powder by grafting of 'dendrimerlike' hyperbranched polymer onto the surface. React Funct Polym 43:341-350.

Visakh PM, Yoshihiko A (2015) Flame retardants: polymer blends, composites, and nanocomposites. Switzerland: Springer International Publishing AG Switzerland.

Wang D et al (2020) A bio-based flame-retardant starch based on phytic acid. ACS Sustainable Chem Eng 8:10265-10274.

Wang GW, Zhuang LH, Sun J, Zheng CL (2014) Salt-free dyeing of ramie fabric with an amino-terminated hyperbranched polymer. Cellulose 21:3725-3736.

Wang P, Cai Z (2017) Highly efficient flame-retardant epoxy resin with a novel DOPO-based triazole compound: thermal stability, flame retardancy and mechanism. Polym Degrad Stab 137:138-150.

Wang X, Romero MQ, Zhang Q, Wang R, Wang DY (2015) Intumescent multilayer hybrid coating for flame retardant cotton fabrics based on layer-by-layer assembly and sol-gel process. RSC Adv 5:10647-10655.

Wang Y, Yan LH (2007) Study on crystal structure and scale behaviors of 2-phosphonobutane-1,2,4tricarboxylic acid. Huaxue tongbao(China) 6:445-449.

Wang ZM, Cai LK (1989) Study on Organic Phosphonic acid and carboxylic acid water quality stabilizer-囚. corrosion and scale inhibition of 2-phosphonobutane-1,2,4-tricarboxylic acid. Journal of East China University of Science and Technology (China), 5:699-705.

Yan YW, Chen L, Jian RK, Kong S, Wang YZ (2012) Intumescence: An effect way to flame retardance and smoke suppression for polystyrene. Polym Degrad Stab 97:1423-1431.

Yuen CWM et al (2007) Using nano- $\mathrm{TiO}_{2}$ as co-catalyst for improving wrinkle-resistance of cotton fabric. Surf Rev Lett 14:571-575. 
Zhang F, Chen Y, Lin H, Wang H, Zhao B (2008) $\mathrm{HBP}^{-\mathrm{NH}_{2}}$ grafted cotton fiber: preparation and salt-free dyeing properties. Carbohydr Polym 74:250-256.

Zhang F, Chen YY, Lin H, Lu YH (2007) Synthesis of an amino-terminated hyperbranched polymer and its application in reactive dyeing on cotton as a salt-free dyeing auxiliary. Color Technol 123:351-357.

Zhang F, Zhang D, Chen Y, Lin H (2009) The antimicrobial activity of the cotton fabric grafted with an amino-terminated hyperbranched polymer. Cellulose 16:281-288.

Zhang JH et al (2020) A bio-based hyperbranched flame retardant for epoxy resins. Chem Eng J $381: 122719$.

Zhang W, He X, Song T, Jiao Q, Yang R (2014) The influence of the phosphorus-based flame retardant on the flame retardancy of the epoxy resins. Polym Degrad Stab 109:209-217.

Zhang WC, Li XM, Fan HB, Yang RJ (2012) Study on mechanism of phosphoruse silicon synergistic flame retardancy on epoxy resins. Polym Degrad Stab 97:2241-2248.

Zhang Z, Kong DZ, Sun H, Sun L, Dong CH, Lu Z (2020) Synthetic novel, convenient and eco-friendly $\mathrm{Si} / \mathrm{P} / \mathrm{N}$ synergistic treatment agent to improve the flame retardancy and thermal stability of cotton fabrics. Cellulose 27:10473-10487.

Zhang Z, Wang HY, Sun J, Guo K (2021) Cotton fabrics modified with Si@hyperbranched poly(amidoamine): their salt-free dyeing properties and thermal behaviors. Cellulose 28:1-15.

Zheng DD, Zhou JF, Zhong L, Zhang FX, Zhang GX (2016) A novel durable and high-phosphorouscontaining flame retardant for cotton fabrics. Cellulose 23:2211-2220.

Zolriasatein AA, Yazdanshenas ME, Khajavi R, Rashidi A, Najafı F (2013) The use of poly(amidoamine) dendrimer in modification of jute for improving dyeing properties of reactive dyes. J Appl Polym Sci 127:4203-4211.

\section{Tables}

Table 1. The element content of P, N, Si in P@PAMAMOS 


\begin{tabular}{|llllllll|}
\hline P@PAMAMOS & PM-PBTC & DMM & DETA & KH560 & \multicolumn{3}{l|}{ Content \% } \\
\cline { 6 - 9 } & & & & & P & N & Si \\
\hline A & 68.0 & 14.4 & 31.0 & 23.6 & 3.05 & 4.13 & 2.76 \\
\hline B & 102 & 0 & 31.0 & 11.8 & 8.40 & 4.8 & 1.20 \\
\hline C & 68.0 & 14.4 & 31.0 & 47.5 & 2.70 & 3.3 & 4.84 \\
\hline
\end{tabular}

Table 2. TG data of blank cotton and $\mathrm{A}_{10}, \mathrm{~B}_{10}, \mathrm{C}_{10}$ treated cotton fabrics in nitrogen atmosphere

\begin{tabular}{|llll|}
\hline Samples & $\mathrm{T}_{\text {onset }}\left({ }^{\circ} \mathrm{C}\right)$ & $\mathrm{T}_{\max }\left({ }^{\circ} \mathrm{C}\right)$ & Residue at $700^{\circ} \mathrm{C}(\%)$ \\
\hline blank cotton & 280 & 370 & 12.7 \\
\hline A $_{10}$ treated cotton & 260 & 330 & 29.5 \\
\hline B $_{10}$ treated cotton & 261 & 315 & 34.5 \\
\hline $\mathrm{C}_{10}$ treated cotton & 262 & 327 & 28.8 \\
\hline
\end{tabular}

Table3. Results of LOI and vertical burning test data for cotton fabrics with different B type P@PAMAMOS concentration.

\begin{tabular}{|lllll|}
\hline $\begin{array}{l}\text { The concentration of } \\
\text { P@PAMAMOS }(\%)\end{array}$ & $\begin{array}{l}\text { LOI } \\
(\%)\end{array}$ & $\begin{array}{l}\text { After flame time } \\
(\mathrm{s})\end{array}$ & $\begin{array}{l}\text { Afterglow time } \\
(\mathrm{s})\end{array}$ & $\begin{array}{l}\text { Char length } \\
(\mathrm{cm})\end{array}$ \\
\hline 0 & 18.0 & 12.3 & 13.4 & - \\
\hline 5 & 24.6 & 0 & 0 & 7.3 \\
\hline 10 & 26.8 & 0 & 0 & 5.1 \\
\hline 20 & 31.2 & 0 & 0 & 3.2 \\
\hline
\end{tabular}

\section{Scheme}

Please see the Supplementary Files for the Scheme 1, 2, 3 and 4

\section{Figures}





\section{Figure 1}

1H NMR spectrum of the P@PAMAMOS before hydrolyzation

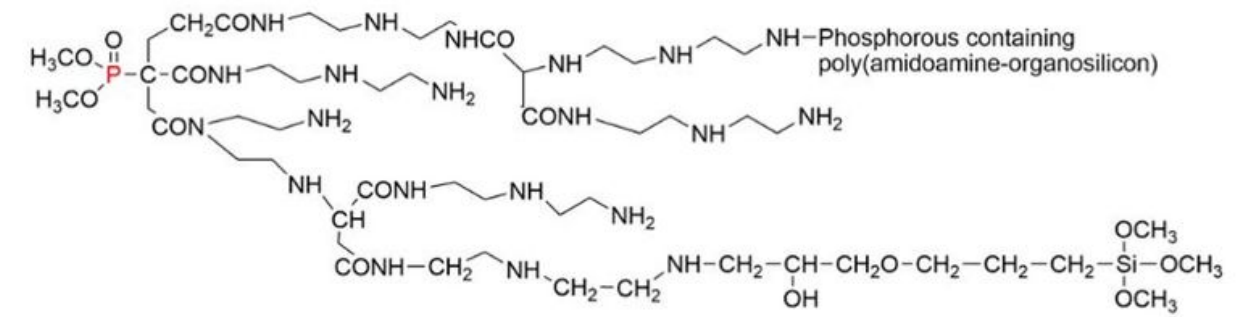

$21 \quad 20$

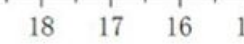

$\begin{array}{llllll}5 & 14 & 13 & 12 & 11 & 10\end{array}$ (ppm)

\section{Figure 2}

31P NMR spectrum of the P@PAMAMOS before hydrolyzation 




Figure 3

FT-IR spectrum of P@PAMAMOS gel 


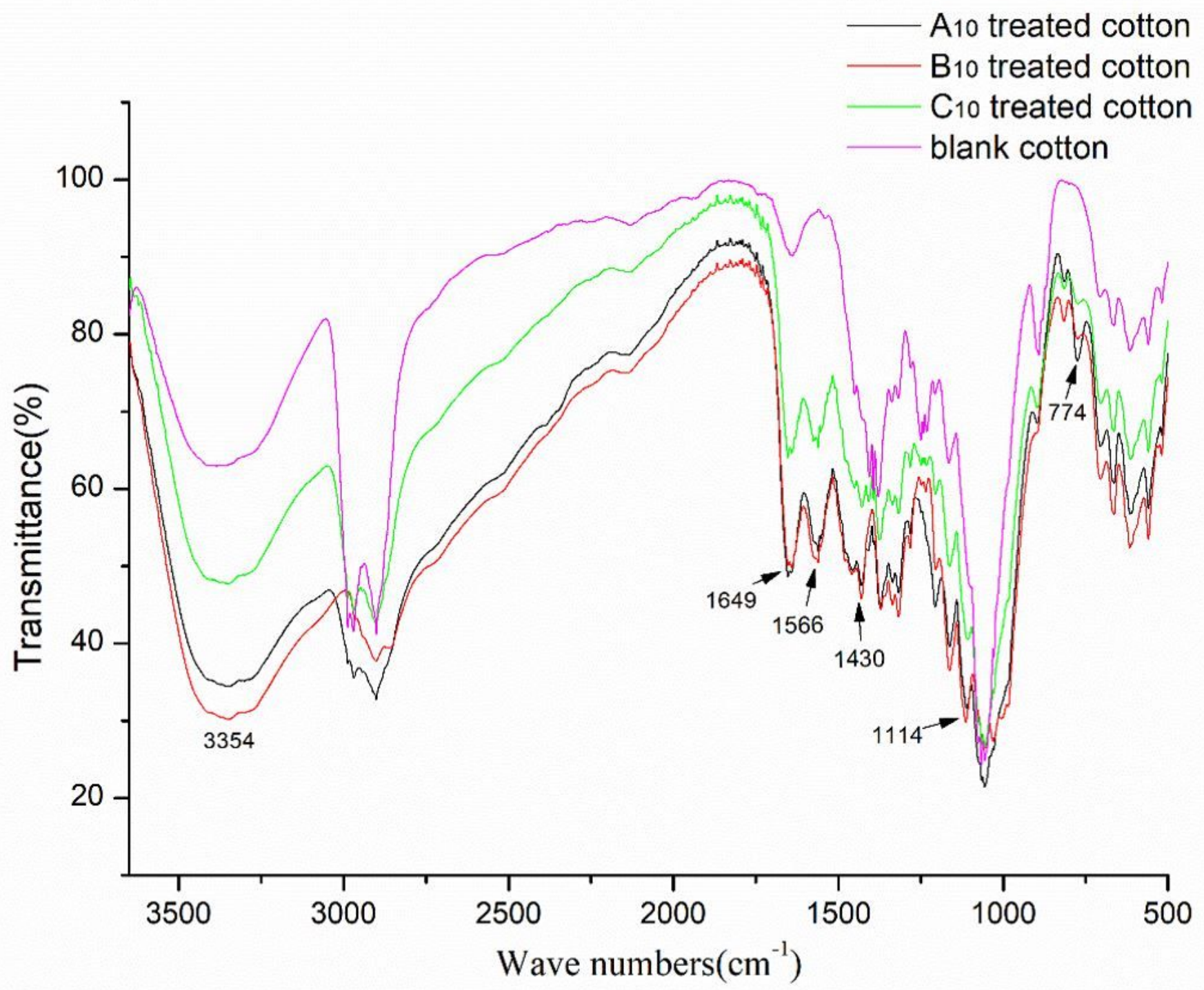

Figure 4

FT-IR spectra of the blank cotton and treated cotton fabrics with different types P@PAMAMOS A10: the cotton fabrics treated with P@PAMAMOS sol of type A in 10\% concentration; B10: the cotton fabrics treated with P@PAMAMOS sol of type B in 10\% concentration; C10: the cotton fabrics treated with P@PAMAMOS sol of type C in 10\% concentration. 



Figure 5

TG and DTG spectra of a, b blank cotton and A10, B10, C10 treated cotton fabrics in nitrogen
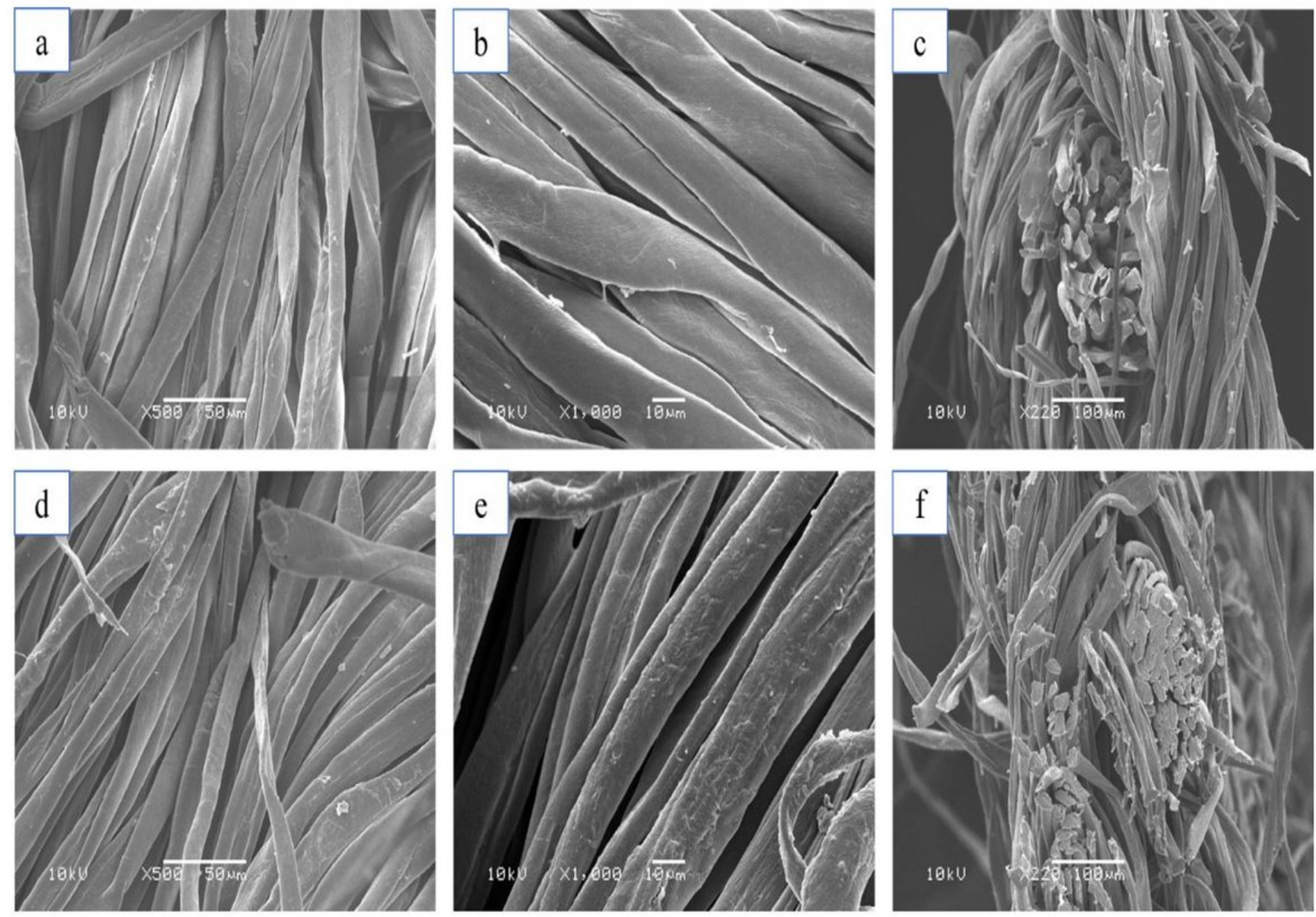
Figure 6

Surface morphologies of blank cotton samples $(a, b, c)$ and B10 modified cotton samples (d, e, f)

Blank cotton

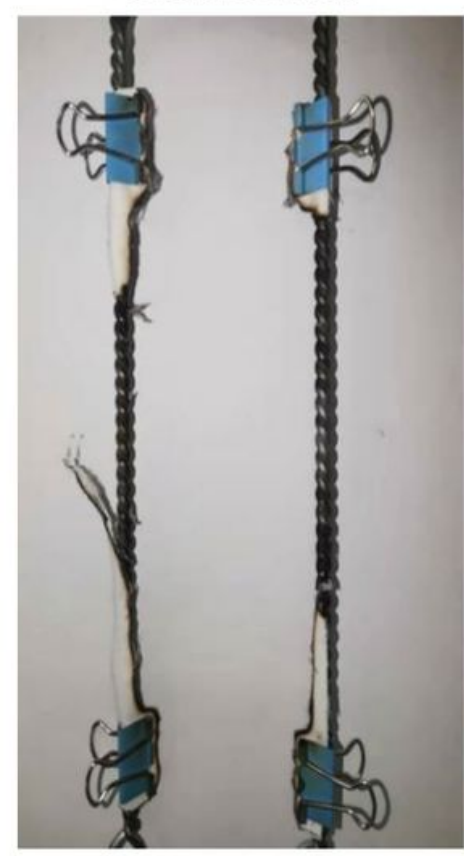

B5 treated cotton



B10 treated cotton

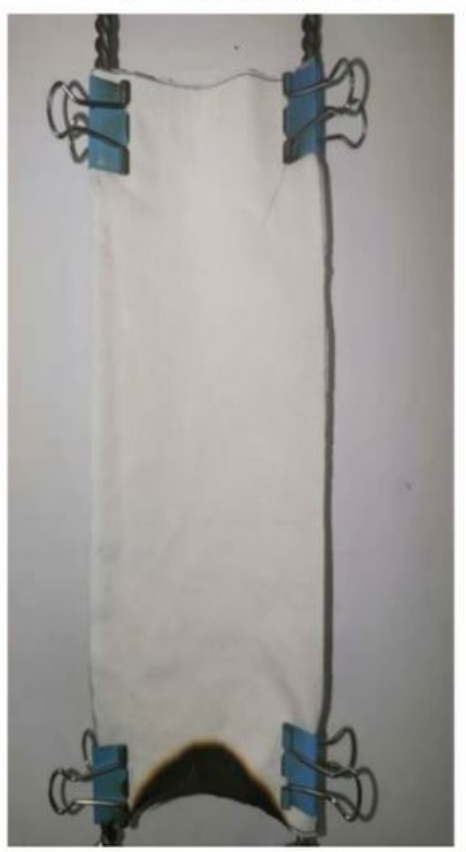

B20 treated cotton

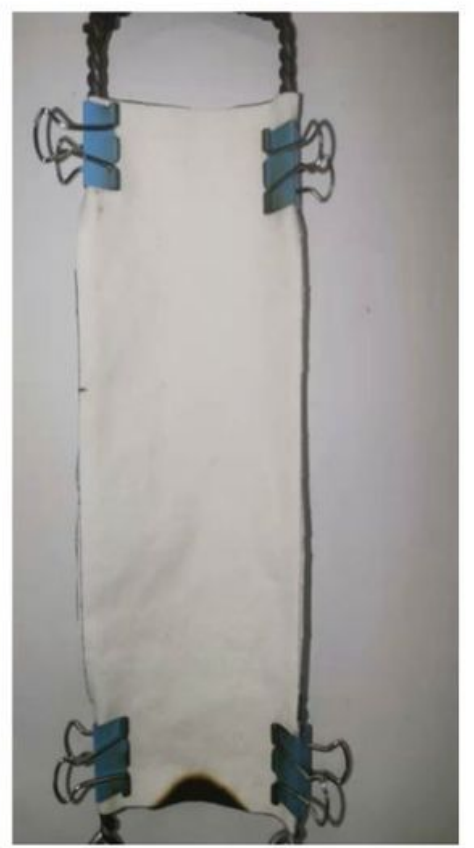

\section{Figure 7}

The results of vertical flammability test of cotton fabrics with different concentrations

\section{Supplementary Files}

This is a list of supplementary files associated with this preprint. Click to download.

- scheme1.jpg

- scheme2.jpg

- scheme3.jpg

- scheme4.jpg 